ORIGINAL PROF-2066

\title{
LOW BIRTH WEIGHT BABIES;
}

Frequently encountered problems at secondary level care

Dr. Kashif Abbas Zaidi, Dr. Nighat Aijaz, Dr. Nasr-ul- Huda

ABSTRACT... Objective: To determine the spectrum of problems in LBW neonates at Secondary care level and their immediate outcome. Design: Descriptive Study. Place \& Duration of Study: Agha Khan Hospital for Women and Children, Kareemabad and Agha Khan Hospital for Women and Children, Kharadar, from January 2009 till December 2009. Results \& Conclusions: Of the 4500 babies born in Agha Khan secondary hospitals, 429 were Low Birth Weight and 191 were admitted to the nursery. The ratio of males to females was 0.86:1.0 (199 males and 230 females). Approximately $41 \%$ of the babies were less than $2 \mathrm{kgs}$ and Preterm babies made up $20.9 \%$ of total low birth weight. Of the 191 babies, 99 (51.8\%) had hyperbilirubinemia ; 16(8.3\%) had respiratory distress syndrome of the newborn; 16(8.3\%) had vomiting and they were observed for necrotizing enterocolitis; $21(10.9 \%)$ had presumed sepsis; 12 (6.2\%) had hypocalcemia; 11 (5.7\%) had hypoglycemia 08 (4.1\%) had Meconium Aspiration Syndrome;; 05 (2.4\%) had thrombocytopenia; and 02 $(1.04 \%)$ had hyperviscosity with hematocrit of more than $65 \%$. Common causes of morbidity in LBW babies are jaundice, sepsis, Respiratory distress, hypoglycemia and hypothermia. Introduction of standard management guidelines aid in reduction of morbidity. With careful selection of cases and predetermined criteria for transfer to the tertiary level nursery, it is possible to care for a vast majority of the newborns in nurseries at secondary level.

Key words: Low Birth Weight, Secondary Level Care, Preterm Babies

Article Citation

Zaidi KA, Aijaz N, Nasr-ul-Huda. Low birth weight babies ; frequently encountered problems at secondary level care. Professional Med J 2013;20(2): 193-198.

\section{INTRODUCTION}

Low birth weight (LBW) has been debated as one of the causes of neonatal death ${ }^{1,2}$. In Pakistan, 25\% of newborns have LBW contributing significantly to neonatal death ${ }^{2,3,4}$ but unfortunately this does not depict the true picture as a lot of babies are delivered at home with no records. Besides mortality, risk of morbidities like respiratory distress syndrome and birth asphyxia is much higher in babies with LBW than their normal birth weight counterparts ${ }^{3}$.

Since it is already known that a large number of the newborn babies are delivered at home in Pakistan. This contributes significantly towards a high perinatal mortality. Therefore, having a Secondary level Mother and ChildCare Hospital with basic health care facilities and a few trained personnel can improve the outcome significantly at a relatively affordable cost. There is a dire need of establishing a network of such units throughout the country especially in the remote areas of Pakistan.

\section{RATIONALE \& OBJECTIVE}

Newborn care at secondary level is slightly different from that of the primary and tertiary care settings. It is extremely important to have a clear idea as to what kind of problems we might be dealing with at the secondary care level so that management guidelines according to the secondary care settings can be tailored.

Our study, therefore, aims to determine the spectrum of problems in LBW neonates at Secondary care level and their immediate outcome. This would help in the development of strategies to improve the outcome of LBW babies in that area.

\section{Inclusion Criteria}

All live born babies delivered at the AghaKhan Hospital for Women and Agha Khan Hospital for Women and Children, Kharadar with birth weight less than 2500 gms. 


\section{Exclusion Criteria}

Children with congenital malformations

\section{Sample Size \& Data Analysis}

It is a descriptive study. The sample size is 429 . All the data was entered in SPSS version of analysis by the primary researchers from the two centres and the total number of low birth weight and their problems were analyzed.

\section{CASE DEFINITION}

Level 2 Nursery: High- dependency neonatal care ( special care newborn nursery)

- $\quad$ Care of infants with a corrected gestational age of 33 weeks or greater or a weight of 1500 gms or greater who are moderately ill with problems expected to resolve quickly or who are convalescing after intensive care.

- $\quad$ Peripheral intravenous infusions and possibly parenteral nutrition for a limited duration.

- $\quad$ Resuscitation and stabilization of all infants before transfer to an appropriate care facility and

- Nasal oxygen with oxygen saturation monitoring (e.g. for infants with chronic lung disease requiring long term oxygen and monitoring)

\section{SUBJECT AND METHOD}

Agha Khan Health Service Hospitals, Sindh, Pakistan, provides secondary level of care both at neonatal as well as maternal level. Each hospital has obstetric and neonatal service. An average of 2000 to 3000 babies are delivered annually with a level care. The nursing care is provided mainly by midwives under the supervision of of one registered nurse in every shift. In each hospital, the nursery has 5-7 incubators, 2-4 head warmers, 2 portable suction machines, pulse oxymeter, phototherapy units and 5-8 cots. The obstetric team provides proper antenatal care. Every delivery is supervised by senior qualified people. In case of low risk delivery, after birth the initial assessment is done by the paediatric doctor within one hour of delivery while in case of high risk delivery every delivery is attended by the paediatric doctor. After the initial assessment the paediatric consultant or Neonatologist reevaluates and takes decision for further care. If any newborn needs level 3 nursing care (like ventilatory support) the baby is then transferred to the tertiary care . Level 2 admits all other babies who need observation or are suffering from prematurity, LBW, respiratory distress, grunting, vomiting, pyrexia, hypothermia, metabolic derangements, birth trauma, Iow APGAR, meconium aspirate, jaundice, congenital anomalies, infant of diabetic mother any other condition of the newborn requiring proper supervision. After stabilization and initiation of feeding, the babies are shifted back to the maternal side. Trend of low birth weight babies in all these secondary level care hospitals of Agha Khan Health Services is $10 \%$. This was estimated by analyzing the registeration system of these hospitals. After registeration of each delivery, proper file of the newborn is made which contains meticulous details of the baby. In case of Small for Gestational Age babies, their weight is plotted on The Badson \& Benda charts ${ }^{7}$ and their maturity is assessed by the New Ballard Score for assessment of fetal maturation of newborn infants. All the perinatal data is recorded in the perinatal register which contains the details of the delivery and the newborn. The register is filled by the obstetric and paediatric doctors for their relevant portions. For our study all the information for the year 2009 on total number of deliveries, low birth weight, gestational age, sex, need of resuscitation, reasons for admission to nursery, APGAR score, any complication requiring anticipation, reason for referral was obtained from the perinatal records. This retrospective detail was then entered in a predesigned performa.

\section{RESULT}

During the period of January 2009 till December 2009, of the 4500 babies born in Agha Khan secondary hospitals, 429 were Low Birth Weight (Table I \& II) and 


\begin{tabular}{|c|c|}
\hline Birth Weight $(\mathbf{k g})$ & Number (\%) \\
\hline $1.5-1.99$ & $176(41 \%)$ \\
\hline $2.0-2.49$ & $253(59 \%)$ \\
\hline
\end{tabular}

Table-I. Distribution of patients by Birth Weight $(n=429)$

\begin{tabular}{|c|c|}
\hline Gestation (weeks) & Number (\%) \\
\hline $34-35$ & $90(20.9 \%)$ \\
\hline $36-36+6$ & $174(40.5 \%)$ \\
\hline 37 & $165(38.4 \%)$ \\
\hline
\end{tabular}

Table-II. Distribution of patients by Gestational age $(n=429)$

191 were admitted to the nursery. The ratio of males to females was 0.86:1.0 (199 males and 230 females).

Approximately $41 \%$ of the babies were less than $2 \mathrm{kgs}$ and preterm babies made up $20.9 \%$ of total low birth weight.

\section{Morbidity}

Of the 191 babies, 99 (51.8\%) had hyperbilirubinemia; $16(8.3 \%)$ had respiratory distress syndrome of the newborn; 16(8.3\%) had vomiting and they were observed for necrotizing enterocolitis ; 21 (10.9\%) had presumed sepsis; 12 (6.2\%) had hypocalcemia; $11(5.7 \%)$ had hypoglycemia 08 (4.1\%) had Meconium Aspiration Syndrome; 05 (2.6\%) had thrombo-cytopenia; and 02 (1.04\%) had hyperviscosity with hematocrit of more than $65 \%$ (Table III).

\section{Outcome}

Of the 191 babies, 03 expired. 02 were discharged against medical advice and 18 were transferred to the nursery in the tertiary hospital or Government Hospital. Of the 03 babies who expired, one baby (pretermer) died of meconium Aspiration Syndrome; one (pretermer) died of sepsis vand respiratory distress syndrome while one term baby died due to birth asphyxia. Among 18 babies who were transferred to tertiary care centre 06 babies were diagnosed with hemolytic disease of the newborn (04 with Rhesus incompatibilty and 02 with $A B O$ incompatibility). These babies required exchange transfusion. 04 pretermers of 33 week gestation had respiratory distress syndrome while 01 preterm with the same gestational age had meconium aspiration syndrome. 01 baby was diagnosed there as possibly having intracranial bleed and hypoxic ischaemic encephalopathy. 02 babies had re-necrotizing enterocolitis. 02 required platelet transfusion due to thrombocytopenia and 01 baby was given partial exchange transfusion due to hyperviscosity syndrome.

\begin{tabular}{|l|c|c|}
\hline \multicolumn{1}{|c|}{ Morbidity } & $\begin{array}{c}\text { Birth weight } \\
\mathbf{( k g )} \\
\mathbf{1 . 5} \mathbf{- 1 . 9 9}\end{array}$ & $\begin{array}{c}\text { Birth weight } \\
\mathbf{( \mathbf { k g } )}\end{array}$ \\
\hline Hyperbilirubinemia & $\mathbf{2 . 4 9}$ \\
\hline Presumed Sepsis & 12 & 40 \\
\hline $\begin{array}{l}\text { Pre-necrotizing } \\
\text { Enterocolities }\end{array}$ & 12 & 09 \\
\hline $\begin{array}{l}\text { Respiratory Distress } \\
\text { Syndrome }\end{array}$ & 12 & 04 \\
\hline Hypocalcemia & 08 & 04 \\
\hline Hypoglycemia & 08 & 03 \\
\hline $\begin{array}{l}\text { Meconium Aspiration } \\
\text { Syndrome }\end{array}$ & 06 & 02 \\
\hline Thrombocytopenia & 04 & 01 \\
\hline Hyperviscosity Syndrome & 02 & - \\
\hline $\begin{array}{l}\text { Hypoxic Ischaemic } \\
\text { Encephalopathy }\end{array}$ & 01 & - \\
\hline $\begin{array}{l}\text { Table-lll. Morbidity of Babies According to Birth Weight } \\
(\mathbf{n}=191)\end{array}$ & \\
\hline
\end{tabular}

\section{DISCUSSION}

Low birth weight neonates may be grossly handicapped at birth by virtue of their weight and in some cases associated relative immaturity of vital 
organs and lack of immunological response ${ }^{1,2}$. This handicap exposes them to high risk of infection, respiratory distress syndrome and other neonatal complications resulting in high rate of perinatal mortality and morbidity ${ }^{2,3,4}$. The incidence of LBW in Pakistan is $16 \%$ to $25 \%{ }^{4}$. This is three to four times higher than that of developed countries 4.5 to $7 \%$ and 2.5 to $4.2 \%(5,6)$. Among these LBW babies, the relative incidence of preterm neonates is lower than that of small for dates neonates $(1.21: 1)^{6}$. In our study, the incidence of preterm babies is low and this is because of the good antenatal care provided at our centre. Majority of LBW in developing countries are small for dates rather than preterm ${ }^{4}$. It is evident from other studies that LBW neonates are a common clinical problem and are associated with a high perinatal mortality and morbidity ${ }^{7,8,9}$. These problems can be prevented to a large extent by early detection and instituting treatment for the underlying problem. Medical care of the sick newborn incurs a high cost due to costly equipments and expensive technology involved $^{10-13}$. Skilled personnel and adequate equipment for newborn care such as resusciteer, warmer, pulse oximetry etc are necessary for a secondary level care centre. It is very important to identify the type of cases that can be adequately managed at such centres so as to reduce the burden from tertiary care centres ${ }^{14}$. In our study, hyperbilirubinemia is a major cause of admission in the secondary care level which is similar to a study done in Bangladesh ${ }^{13,15}$. Among them very small percentage required tertiary care for exchange transfusion. Presumed sepsis was the second most common condition requiring admission in the secondary care but it comprised $23 \%$ of overall admission while other studies showed higher percentage $^{16,17,18}$. This difference could be due to the level of antenatal and postnatal care in our setup. We offer proper screening, aseptic delivery measures and follow American Academy guidelines for Group B streptococcal infections. In our study $8.3 \%$ babies were admitted due to vomiting. These babies were thoroughly screened for sepsis and necrotizing enterocolitis. Among them $12 \%$ were shifted to tertiary care level. Most of the case of vomiting were due to improper feeding techniques and mothers were then counceled and trained for that. In our study, hypoglycemia and hypocalcemia were the only metabolic abnormalities found, as also seen in other studies $^{19,20}$. Thrombocytopenia was seen only in those cases which had developed sepsis and polycythemia due to hyperviscosity syndrome. This is consistent with an Indian study ${ }^{20}$. Hypothermia was another problem affecting three of the cases; two of these cases had only one episode. In our study , out of 191 babies 02 expired. One was preterm, Low Birth Weight baby who developed birth asphyxia and sepsis. The other baby had meconium aspiration syndrome and he had also developed pulmonary hypertention. These two expiries occurred at the tertiary care as we had transferred these babies there. We can see from our study that only 17 babies required transfer to a tertiary care centre and most of the babies could be very well managed here at the secondary care level thereby reducing the burden on tertiary care centres.

\section{CONCLUSIONS}

Common causes of morbidity in LBW babies are jaundice, sepsis, Respiratory distress, hypoglycemia and hypothermia. Introduction of standard management guidelines aid in reduction of morbidity. With careful selection of cases and predetermined criteria for transfer to the tertiary level nursery, it is possible to care for a vast majority of the newborns in nurseries at secondary level.

Copyright@ 24 Dec, 2012.

\section{REFERENCES}

1. S.A. Rizvi, J. Hatcher, I. Jehan and R. Qureshi. Maternal risk factors associated with low birth weight in Karachi: a case-control study. Health Journal Volume 13 No. 6 November - December, 2007.

2. Bhutta ZA. Priorities in newborn care and development of clinical neonatology in Pakistan: 
where to now? J Coll Physician Surg Pak 1997;7:2314.

3. Parkash J, Das N. Pattern of admission to neonatal unit. J Coll Physician Surg Pak 2005;15:341-44.

4. Rahim F, JanA, Mohummad J, Hamid I. Pattern and outcome of admissions to neonatal unit of Khyber Teaching Hospital, Peshawar. Pak J Med Sci April 2007 Vol. 23 No. 2 249-253.

5. World Health Organization. World health report 2005. Make every mother and child count. www.who.int/whr/2005/en/index.html (accessed 26 Jul 2006).

6. Unicef. Monitoring the status of women and children. www.childinfo.org/ (accessed 26 Jul 2006).

7. Fenton TR: A new growth chart for preterm babies: Badson and Benda chart updated and a new format. BMC Pediatr 3:13, 2003.

8. ASM Nawshad Uddin Ahmed, MA Rob, Ferdous Rahman, Redwanur Rahman, Nazmul Huda. Preterm Very Low-Birth Weight Babies: Outcome of Admitted Newborns at a Community-Level Medical College Hospital in Bangladesh. J Bangladesh Coll Phys Surg 2008; 26: 128-134.

9. Naveed Zafar Janjua, Elizabeth Delzell, Rodney R Larson, Sreelatha Meleth, Sibylle Kristensen, Edmond Kabagambe and Nalini Sathiakumar. Determinants of low birth weight in urban Pakistan. Public Health Nutrition, 2009;12, pp 789-798.

10. Sohely Yasmin, David Osrin, Elizabeth Paul \& Anthony Costello. Neonatal mortaliy of low birth weight infants in Bangladesh. Bulletin of the World Health Organization 200179.

11. Kavitha Balaji, Sathish Sankar and Balaji Nandagopal. Low Birth Weight of Newborns: Magnitude of the Problem Seen in a 100 Bed Hospital of a Rural Area in
Vellore District, Tamil Nadu Received March 19, 2009 Accepted March 18, 2010.

12. Chhabra P, Sharma AK, Grover VL, Aggarwal OP. Prevalence of low birth weight and its determinants in an urban resettlement area of Delhi. Asia Pac J Public Health. 2004;16:95-8.

13. M. I Bari, M. A Ullah, M Khatun. Morbidity and Mortality of Low Birth Weight Baby. TJA 2008;21(!):35-39.

14. Zupan $\mathrm{J}$. Perinatal mortality in developing countries. New England Journal of Medicine 2005; 352: 2047-2048

15. ASM Nawshad Uddin Ahmed, MA Rob, Ferdous Rahman, Redwanur Rahman, Nazmul Huda. Preterm very low-birth weight babies: Outcome of Admitted Newborns at a Community-Level Medical College Hospital in Bangladesh. J Bangladesh Coll Phys Surg 2008; 26: 128-134.

16. Mavalankar DV, Gray RH, Trivedi CR. Risk factors for preterm and term low birthweight in Ahmedabad, India. Int J Epidemiol. 1992 Apr;21(2):263-72.

17. Das BK, Mishra RN, Mishra OP, Bhargava V, Prakash A. Comparative outcome of low birth weight babies. Indian Pediatr. 1993 Jan;30(1):15-21.

18. RB Gurav, S Kartikeyan, MR Jape: Low birth weight babies - A Pilot Study Santosh K. Bhargava and Jai Kishan Low birth weight and its sequelae : The Indian experience Indian J Pediatr 47, 117-1211980.

19. Santosh K. Bhargava and Jai Kishan. Low birth weight and its sequelae: The Indian experience Indian J Pediatr 1980; 47,117-121.

20. S. Ganesh Kumar, H. N. Harsha Kumar, S. Jayaram and M. S. Kotian. Determinants of low birth weight: A case control study in a district hospital in Karnataka. Indian J Pediatr 2009 Jan 77, (1), 87-89. 


\section{AUTHOR(S):}

1. DR. KASHIF ABBAS ZAIDI

Assistant Professor Paediatrics

Liaquat National Hospital

2. DR. NIGHAT AIJAZ

Assistant Professor Paediatrics

Liaquat National Hospital

3. DR. NASR-UL- HUDA

Sr. Lecturer

Dow University of Health Sciences
Correspondence Address:

Dr. Kashif Abbas Zaidi

Assistant Professor Paediatrics

Liaquat National Hospital

aun_raza40@yahoo.com

\section{PREVIOUS RELATED STUDIES}

Uzma Urooj, Shehla Baqai, Asma Ansari. PREGNANT WOMEN WITH LOW BMI (<19); FREQUENCY OF PRETERM LABOURAND LOW BIRTHWEIGHT (Original) Prof Med Jour 18(4) 592-597 Oct, Nov, Dec 2011.

\section{CORRECTION}

The amendment of the Professional Vol: 20, No.01 (Prof-1963) titled: "Neonatal resuscitation; impact of neonatal resuscitation programmes on birth asphyxia, the actual situation" on page 78 and 84 is as under;

\section{INCORRECT}

Dr. Fauzia Zafar, Dr. Muhammad Azam Khan, Dr. Abdul Ghaffar FiazAhmad

1. DR. FAUZIA ZAFAR

Associate Professor

Pediatric Medicine Unit-I

Nishtar Medical College \& Hospital, Multan

2. DR. MUHAMAMD AZAM KHAN

3. DR. ABDUL GHAFFAR FIAZ AHMAD

\section{CORRECT}

Dr. Fauzia Zafar, Dr. Abdul Ghaffar, Dr. Muhammad Azam Khan

\section{DR. FAUZIA ZAFAR}

Associate Professor

Pediatric Medicine Unit-I

Nishtar Medical College \& Hospital, Multan

2. DR. ABDUL GHAFFAR

3. DR. MUHAMAMD AZAM KHAN
Article received on: 16/08/2012 Accepted for Publication: $\quad$ 24/12/2012 Received after proof reading: 03/02/2013

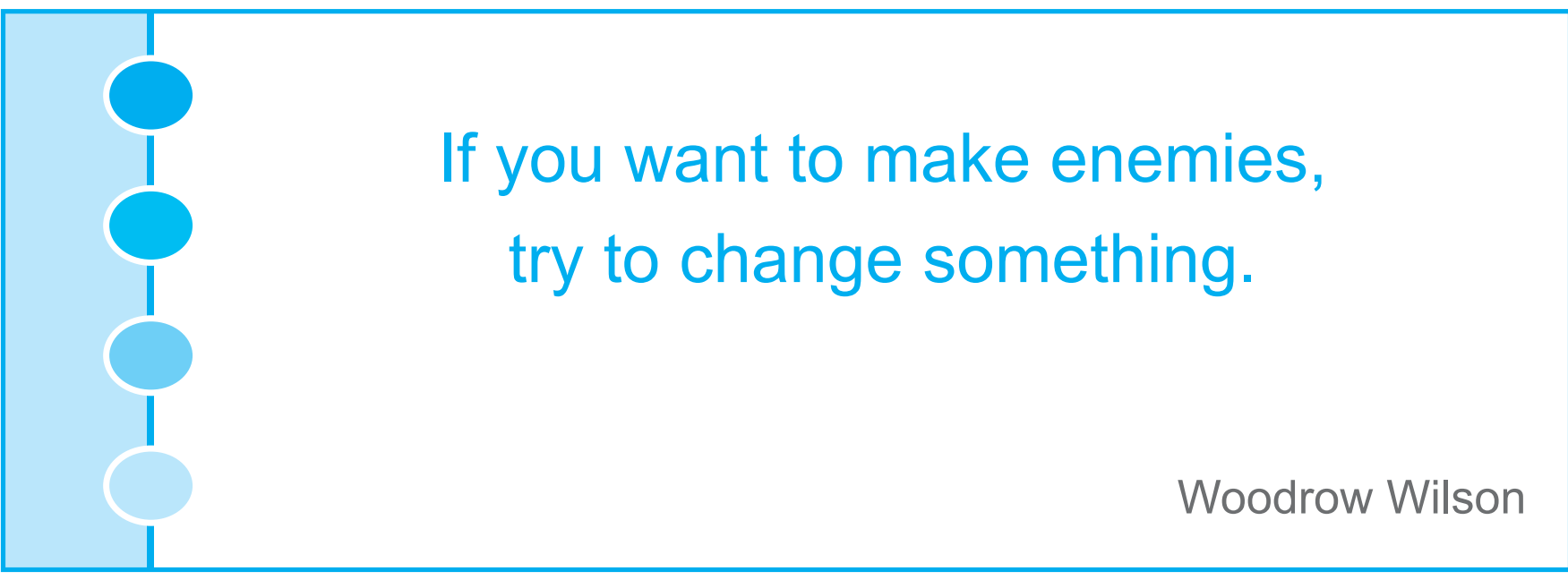

